\title{
Green Synthesis, Characterization of Zinc Oxide Nanoparticles, and Examination of Properties for Dye-Sensitive Solar Cells Using Various Vegetable Extracts
}

\author{
Anatol Degefa, ${ }^{1}$ Bulcha Bekele, ${ }^{2}$ Leta Tesfaye Jule, ${ }^{2,3}$ Boka Fikadu, ${ }^{2}$ \\ Shanmugam Ramaswamy, ${ }^{4}$ Lalitha Priyanka Dwarampudi, ${ }^{5}$ N. Nagaprasad $\left({ }^{6},{ }^{6}\right.$ \\ and Krishnaraj Ramaswamy $\mathbb{1}^{3,7}$ \\ ${ }^{1}$ Department of Mathematics, College of Natural and Computational Science, Dambi Dollo University, Ethiopia \\ ${ }^{2}$ Department of Physics, College of Natural and Computational Science, Dambi Dollo University, Ethiopia \\ ${ }^{3}$ Centre for Excellence-Indigenous Knowledge, Innovative Technology Transfer and Entrepreneurship, \\ Dambi Dollo University, Ethiopia \\ ${ }^{4}$ TIFAC CORE HD, Department of Pharmacognosy, JSS Academy of Higher Education and Research, JSS College of Pharmacy, Ooty, \\ Tamil Nadu, India \\ ${ }^{5}$ Department of Pharmacognosy, JSS Academy of Higher Education and Research, JSS College of Pharmacy, Ooty, \\ Tamil Nadu, India \\ ${ }^{6}$ Department of Mechanical Engineering, ULTRA College of Engineering and Technology, Madurai, Tamil Nadu, India \\ ${ }^{7}$ Department of Mechanical Engineering, College of Engineering, Dambi Dollo University, Ethiopia
}

Correspondence should be addressed to Krishnaraj Ramaswamy; prof.dr.krishnaraj@dadu.edu.et

Received 8 July 2021; Revised 29 July 2021; Accepted 7 August 2021; Published 26 August 2021

Academic Editor: Shanmugam Rajeshkumar

Copyright ( $) 2021$ Anatol Degefa et al. This is an open access article distributed under the Creative Commons Attribution License, which permits unrestricted use, distribution, and reproduction in any medium, provided the original work is properly cited.

\begin{abstract}
The production of zinc oxide nanoparticles (ZnO NPs) utilizing different vegetable extracts (onion, cabbage, carrot, and tomato) was performed in this research owing to its excellency over other methods of synthesis, namely, simplicity, environmental friendliness, and the elimination of harmful compounds. Fresh extracted onion, cabbage, carrot, and tomato of $\mathrm{ZnO} \mathrm{NPs}$ are characterized by Fourier transform infrared (FTIR), X-ray diffraction (XRD), scanning electron microscopy (SEM), and UVvisible spectroscopy. FTIR findings demonstrate that the prepared nanoparticles were observed in the spectrum of $626 \mathrm{~cm}^{-1}-$ $1219 \mathrm{~cm}^{-1}$ with some other functional groups. Wurtzite hexagonal structure of the prepared ZnO NPs was observed from XRD results. In addition, the prepared nanoparticles were failed into nanoscales $(17 \mathrm{~nm}, 18 \mathrm{~nm}, 24 \mathrm{~nm}$, and $15 \mathrm{~nm})$ calculated from Scherrer's equation. Nearly spherical shapes were seen from SEM image for onion and tomato extraction while rod and tube for carrot and cabbage, respectively. Two broad peaks were observed from UV-vis spectroscopy results for each extract. The presence of a wide range of energy bandgaps in the region of $3-4 \mathrm{eV}$ was detected, indicating that $\mathrm{ZnO} \mathrm{NP}$ material can be employed in metal oxide semiconductor-based systems. The dye-sensitive solar cell based on ZnO NPs has been successfully synthesized, and the efficiency of the device has been evaluated by measuring the current density-voltage behaviour under the presence of artificial sunshine. The increased effectiveness of the manufactured dye-sensitive solar cell is attributable to a large improvement in dye molecular adsorption onto the surface of $\mathrm{ZnO}$ NPs. Thus, the usage of the green produced ZnO NPs with creating dye sensitivity solar cell is a simple and viable way for the well-being of our future.
\end{abstract}

\section{Introduction}

Power originates in numerous forms as a result of burning forests to produce fire in ancient times to electrical produc- tions in the contemporary era. Its usage is among the most significant aspects in everyday living interaction of human beings. Nevertheless, the primary resources of energy that human beings utilized in the reaping have exhibited signs 
of insufficiency due to the rise in industrial development in a large number of countries. As an outcome, growing concerns about energy crisis, global warming, lack in fossil fuels, and environmental problems are encouraging the research work to produce clean, affordable, and sustainable sources of the energy that will propel the world into the future [1]. Latest advancement in solar energy transformation innovations that use biosemiconductors as the light harvesting layer makes use of metallic oxide semiconductor (MOS) nanostructures for reliability. Both electrode and the biomolecules are involved in charge extraction and transportation, according to the National Renewable Energy Laboratory [2]. Nanoscience is a broad topic that concerns of the research and implementation of materials on a nanoscale. It is becoming increasingly popular. When compared to their bulk counterparts, nanoparticles (NPs) demonstrate new and enhanced qualities as a result of changes in their characteristics such as form size, size distribution, and a greater measure of the relationship between surface area and volume [3]. Metal nanoparticles (metal NPs) have found a wide range of applications in the fields of science and innovation in recent years, owing to their distinctive electrical, mechanical, optical, and magnetic characteristics [1-3]. Because of its vital applications as antibacterial agents, photovoltaic cells, textile fabrics, and polymers to eradicate microorganisms, zinc oxide nanoparticles (ZnO NPs) have garnered a considerable deal of interest from researchers in recent years [3].

The need for environmentally friendly energy sources has prompted extensive study into nanomaterials to meet these needs. When it comes to technology, nanotechnology is a branch that analyzes diverse materials on a nanometric scale. Its applications can be discovered in materials science, engineering, and electronic engineering. Nanoparticles exhibit a wide range of magnetic and optoelectronic properties that are influenced by their size and form distribution, as well as their composition. Due to the fact that this technique of synthesis eliminates the need for harmful chemicals, as well as its ease and environmental friendliness, the synthesis of nanoparticles employing vegetable extract is becoming increasingly popular [3-5]. In addition to its unique characteristics and high excitonic binding energy, zinc oxide $(\mathrm{ZnO})$ is used in this application [1-5].

It is routinely possible to synthesize $\mathrm{ZnO}$ NPs using various methods, including but not limited to hydrothermal, solvothermal, sol-gel, direct oxidation, chemical vapour deposition (CVD), electrodeposition (ED), sonochemical, chemical bath deposition (CBD), microwave, and other approaches [5]. These approaches, on the other hand, are expensive, hazardous, and unfriendly to the natural environment. Nowadays, there is a growing demand for developing $\mathrm{ZnO}$ that has excellent yielding, has moderate cost, and is nontoxic by utilizing biological sources and environmentally acceptable techniques of exploration and production. To synthesize zinc oxide nanoparticles using a green synthesis approach, environmentally friendly resources including such plant extracts (leaf/flower/bark/root/seed/peel) and also the bacteria/fungi/enzymes are used for the manufacture of zinc oxide nanoparticles [6]. Vegetable removal was employed in this investigation due to its plentiful affordability. It has been observed that diverse vegetable extracts can be used to pro- duce zinc oxide nanoparticles [6-8]. Different scholars have documented the usage of $\mathrm{ZnO}$ NPs in the production of dyesensitive solar cells in their research. The green synthesis of zinc oxide nanoparticles employing onion, cabbage, carrot, and tomatoes as a resource for dye-sensitive solar cell implementation has not been documented, and no comparisons have been done between them. In the present research, $\mathrm{ZnO}$ nanoparticles are synthesized using the green synthesis technique, with preparations of tomato, onion, cabbage, and carrot serving as reducing and stabilising agents in addition to the $\mathrm{ZnO}$. The nanoparticles that were synthesized were analyzed using a variety of techniques, including Fourier transform infrared, X-ray diffraction, scanning electron microscopy, and an ultraviolet/visible spectroscope. One of the objectives of this research is to synthesize and analyze zinc oxide nanoparticles based on extracts of onion and cabbage. Another is in order to look into the use of zinc oxide nanoparticles in the manufacture of dye-sensitive solar cells utilizing extracts of carrot and tomato.

\section{Experimental Details}

2.1. Synthesis Methods. Fresh onion, carrot, cabbage, and tomato were acquired in a market of Dambi Dollo Town. Zinc acetate dihydrates (99.7\%) and ethanol (99.5\%) as a solvent were also purchased from the market. First, the onion, cabbage, carrot, and tomato were chopped into tiny slices and rinsed three times with distilled water. Next, the onion, cabbage, carrot, and tomato were weighed and blended into the distilled water, and the process was repeated three more times. Aqueous extracts were obtained after mixing 22 grams of onion powder, 30 grams of cabbage powder, 20 grams of carrot powder, and 22 grams of tomato powder in 200 millilitres of distilled water in various beakers for 20 minutes at a time until the mixtures came to a boil. Following freezing, the combinations were filtered through what man paper and kept at $40^{\circ} \mathrm{C}$ until they were needed for another application. The green syntheses of $\mathrm{ZnO}$ NPs were performed out in accordance with published procedures [9]. $2 \mathrm{M}$ concentration of zinc acetate dihydrate $\mathrm{Zn}\left(\mathrm{CH}_{3} \mathrm{COO}\right)_{2} \cdot 2 \mathrm{H}_{2} \mathrm{O}$ was made in a beaker using sonication to dissolve $15 \mathrm{~g}$ of $\mathrm{Zn}\left(\mathrm{CH}_{3} \mathrm{COO}\right)_{2} \cdot 2 \mathrm{H}_{2} \mathrm{O}$ in 1 litre of distilled water. The mixture was stored in the refrigerator until it was needed. The preparations of onion $(10 \mathrm{~mL})$, tomato $(10 \mathrm{~mL})$, cabbage $(10 \mathrm{~mL})$, and carrot $(10 \mathrm{~mL})$ were combined with a $10 \mathrm{~mL}$ solution of $\mathrm{Zn}\left(\mathrm{CH}_{3} \mathrm{COO}\right)_{2} \cdot 2 \mathrm{H}_{2} \mathrm{O}$ in a beaker using a stirrer for 10 minutes and then allowed to stand at room temperature for $24 \mathrm{~h}$ before testing. The decrease of $\mathrm{Zn}$-ion was seen as a change in colour from white to pale brown and then to a deep brown over time, as shown by the shifting of colour to white to light brown and then to dark brown. Because of the manufacture of $\mathrm{ZnO}$ NPs, the texture of the mixture had been changing. In the following 24 hours, the produced nanoparticles were whirled at $12000 \mathrm{rpm}$ for 15 minutes and rinsed six times using ethanol and distilled water before being used. Following collection of the samples, they were moved to a Petri dish and dried for 12 hours at $70^{\circ} \mathrm{C}$ in a vacuum oven. 


\subsection{Characterization Techniques}

2.2.1. FTIR Analysis. In order to study and characterize the connected functional groups to a surface of the synthesized $\mathrm{ZnO}$ nanoparticles, the PerkinElmer FTIR Spectrum One was used with a scanning spectrum of $4000-400 \mathrm{~cm}^{-1}$ and a resolution of $4 \mathrm{~cm}^{-1}$ for the analysis of the connected functional groups to the exterior of the synthesized $\mathrm{ZnO}$ nanoparticles. For both the FTIR evaluations, the specimen was consistently and appropriately mixed with solid $\mathrm{KBr}$, which was squeezed to settle down on an extremely thin film, and this relatively thin film was used for the FTIR analysis, which was stored in the scanning chamber of the instrument.

2.2.2. X-Ray Diffraction and SEM Analysis. The X-ray diffraction (XRD) distribution of $\mathrm{ZnO}$ nanoparticles was acquired using an X'Pert Pro X-ray diffractometer that generated $\mathrm{Cu} \mathrm{K} \alpha$ radiation (with an angular resolution of 1.5418 angstrom). It is being employed to evaluate the crystalline particle sizes that have been manufactured. For the purposes of characterization, a tiny quantity of powder sample was used. At room temperature, X-ray generators were running at a voltage of $40 \mathrm{kV}$ and applying a current of $30 \mathrm{~mA}$ to the target. Temperature-dependent strengths were recorded at ambient temperature in steps of 0.02 , throughout a range of 100 to $800^{\circ} \mathrm{C}$, with the diffractometer attached to a computer for data collection and characterization displays. It was necessary to authenticate the structure of the crystal by comparing its peak positions with those of the existing standard data. For each sample, about $0.6 \mathrm{~g}$ of the produced $\mathrm{ZnO}$ NPs was ground to tiny powders and quantified using a beam balance before being transferred to a metal plate. Once the nanoparticles had been formed, the particle morphology was examined by utilizing a scanning electron microscope (Hitachi, H-7600) that operates under high vacuum and has magnifications ranging from $20 \mathrm{x}$ to about $30,000 \mathrm{x}$, as well as spatial resolutions of 50 to $100 \mathrm{~nm}$. Greater magnification of $\mathrm{ZnO}$ NPs was attained by decreasing the raster width of the sample, and vice versa, for the fixed sizes of the ZnO NPs. A quartz cuvette with a diameter of $1 \mathrm{~cm}$ was used to measure the absorbance spectra of obtained ZnO NPs employing UV-vis spectroscopy (PerkinElmer LAMBDA 950), which was operated throughout a wavelength range of 200-500 $\mathrm{nm}$. Approximately $0.3 \mathrm{~g}$ of $\mathrm{ZnO}$ NPs was mixed with double distilled water before being placed into a quartz cuvette to form their solutions. After that, the cuvette was placed in an ultraviolet visible spectrophotometer, where the absorption spectra of $\mathrm{ZnO}$ NPs were determined.

\section{Results and Discussion}

3.1. FTIR Analysis. In order to identify the probable functional groups in biomolecules contained with the presence of a natural extract that are due to the reduction of the zinc ion into $\mathrm{ZnO}$ NPs, a Fourier transform infrared spectral analysis (FTIR) was performed. FTIR spectra of the prepared $\mathrm{ZnO}$ NPs with vegetable extracts are observed in Figure 1. FTIR spectrum of ZnO NPs synthesized with onion, cab- bage, carrot, and tomato extracts demonstrated almost the absorption peaks at $626,1219,1392,1744$, and $2361 \mathrm{~cm}^{-1}$. The N-H, O-H, and H-bonded phenols and alcohols stretching oscillations of amide groups are represented because of the powerful and broad peak at $1500-2000 \mathrm{~cm}^{-1}$, which corresponds to the $\mathrm{N}-\mathrm{H}, \mathrm{O}-\mathrm{H}$, and $\mathrm{H}$-bonded phenols and alcohols stretching vibrations of amide groups, respectively. The C-O stretch oscillations are represented by the bands that occur in the vicinity of $2361 \mathrm{~cm}^{-1}$. The appearance of a band in the spectrum in the ranges of $626 \mathrm{~cm}^{-1}$ to $1219 \mathrm{~cm}^{-1}$ indicates the formation of $\mathrm{ZnO}$ NPs, and the results are in great deal with the literature [10-12].

3.2. X-Ray Diffraction Analysis. The XRD pattern of $\mathrm{ZnO}$ NPs that were generated utilizing samples of onion, cabbage, carrot, and tomato is presented in Figure 2, and it can be seen in Figure 3. In accordance with JCPDS card no. 361451, all XRD diffraction profiles of $\mathrm{ZnO}$ NPs are all in excellent accordance with the hexagonal wurtzite architecture (hexagonal phase, space group P63mc) having lattice parameters of $a=b=3.249$ and $c=5.206$ as described in the retrieved products $[10,12,13]$. Two broad diffraction peaks were observed at $27.39^{\circ}$ and $40.64^{\circ}$ with corresponding crystal planes of (100) and (002), respectively. Here, the onion-extracted nanoparticles have shown two broad peaks only. In addition, $47.31^{\circ}, 53.60^{\circ}, 72.63^{\circ}$, and $73.75^{\circ}$ were observed with (101), (102), (200), and (112) of crystal planes, respectively, in all the extracted samples except in the case of onion. The most intense peak was observed at (100) and shows the preferred growth plane; therefore, it demonstrated to the high level of purity of $\mathrm{ZnO} \mathrm{NP}$ products. The XRD pattern of green synthesized ZnO NPs reported in the literature [14] is incongruous in accordance with the trend illustrated in Figure 2. Thus, utilizing XRD, the formation of $\mathrm{ZnO}$ NPs was established. The dimensions of the nanoparticles were determined using the assistance of the following Scherrer's equation.

$$
t=\frac{0.9 \lambda}{\beta \cos \theta},
$$

where $t$ is the mean dimension of nanoparticles, $k$ is the frequency of radiation, $\beta$ is the whole width half peak in radians, and $\theta$ is the degree diffraction [12-14].

Onion, cabbage, carrot, and tomato preparations have been used to synthesize nanoparticles with mean sizes of $17 \mathrm{~nm}, 18 \mathrm{~nm}, 24 \mathrm{~nm}$, and $15 \mathrm{~nm}$, respectively. The average sizes of the nanoparticles produced with onion, cabbage, carrot, and tomato extracts are seen in Table 1. Based on the foregoing findings, it can be inferred that throughout the instance of tomato extracts, smaller nanoparticles are generated.

3.3. SEM Analysis. Figure 3 demonstrates the SEM morphology of the extracted $\mathrm{ZnO}$ nanoparticles synthesized by onion, cabbage, carrot, and tomato, respectively. SEM images depict the spherical surface morphology in the case of onion and tomato extractions, while nearly nanorod and nanotube are synthesized using carrot and cabbage, 


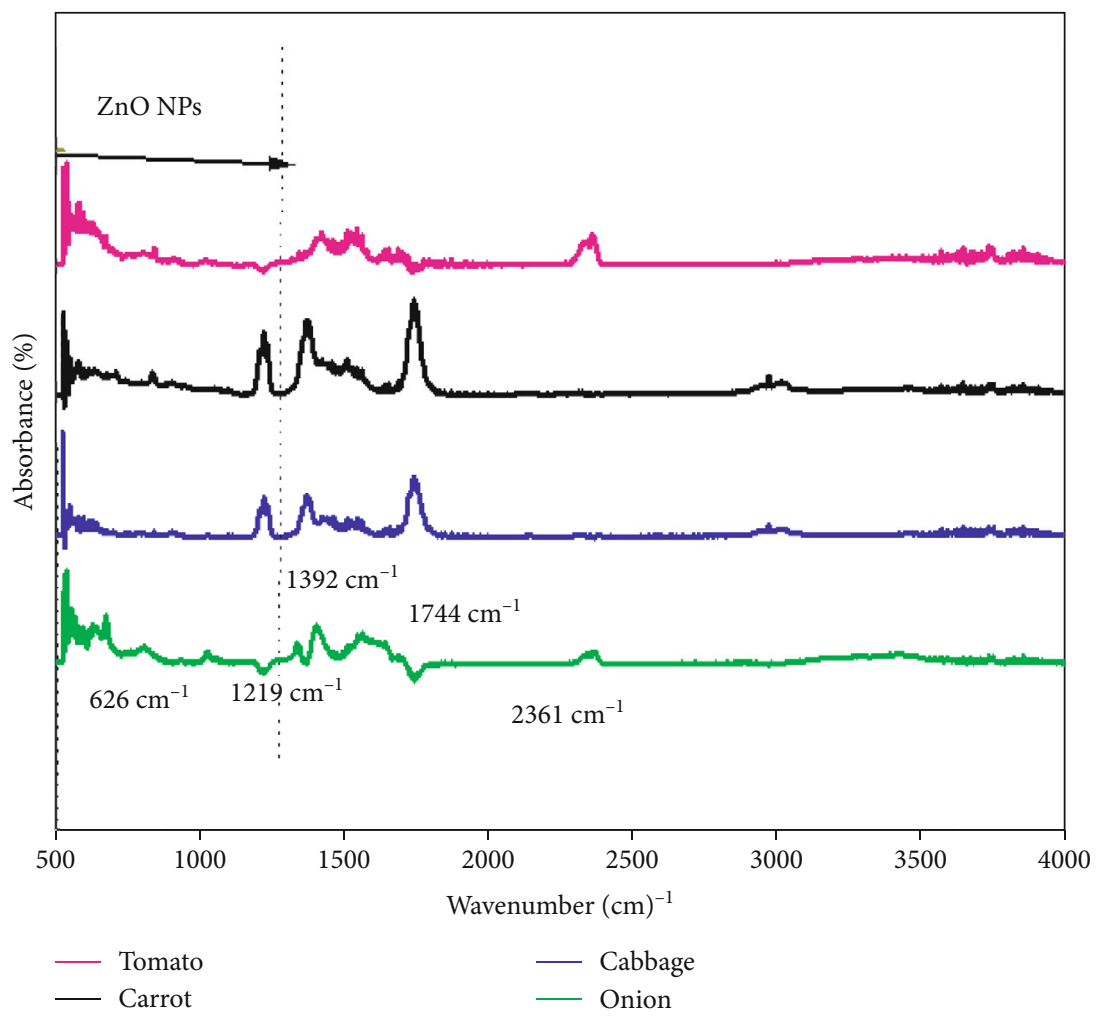

FIGURE 1: FTIR spectra of onion-, cabbage-, carrot-, and tomato-extracted ZnO NPs by green synthesizing methods.

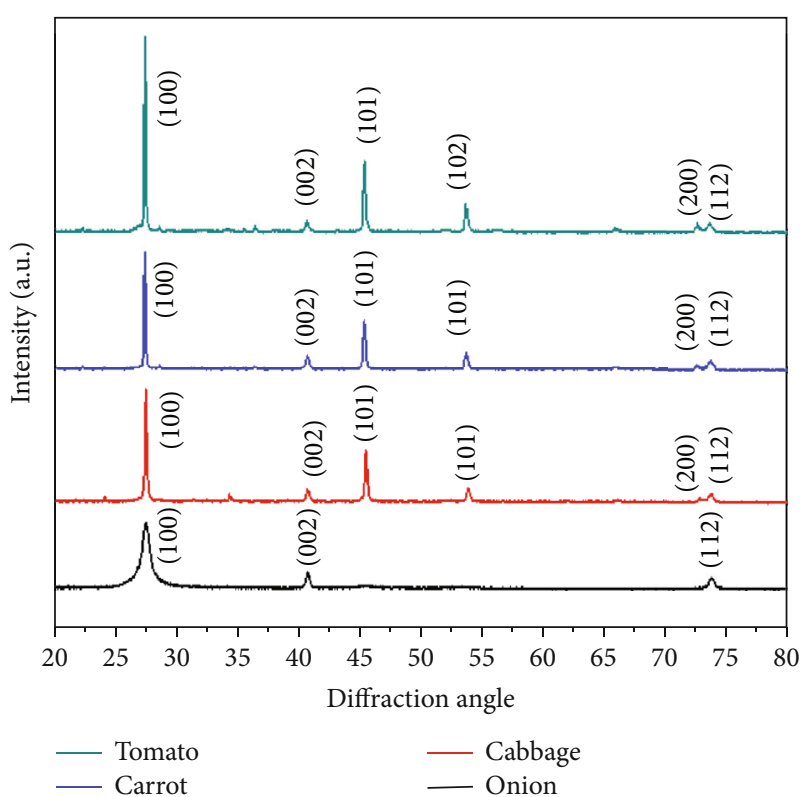

FIGURE 2: XRD spectral analysis of the prepared ZnO NPs extracted from onion, cabbage, carrot, and tomato.

respectively. Because of their small size, the green synthesized structures are uniform in nature, with little aggregation. Instead of using costly and harmful capping agents to minimize agglomeration, plant extract works as a reducing agent as well as a capping agent. As a result, this process is more cost-effective and environmentally benign than the other certain technique of producing $\mathrm{ZnO}$ NPs. The narrow assimilation SEM image in onion and tomato extracts of the prepared $\mathrm{ZnO}$ NPs depicts detail wurtzite hexagonal structure where their adjacent contacting surface is smooth and has well-defined shapes [15-18].

The optical bandwidth of the produced ZnO NPs was studied using UV-vis spectroscopy [16, 18]. To obtain a homogeneous solution, the produced $\mathrm{ZnO}$ NPs were scattered evenly in the triple filtered water employing an ultrasonicator for 5 minutes. The UV-visible spectrum of the green produced $\mathrm{ZnO}$ NPs retrieved from onion, cabbage, carrot, and tomato is shown in Figure 4. The spectrum reveals a wide absorption peak at $276 \mathrm{~nm}$ and $375 \mathrm{~nm}$ for onionextracted nanoparticles. In addition, $217 \mathrm{~nm}$ and $310 \mathrm{~nm}$, $214 \mathrm{~nm}$ and $338 \mathrm{~nm}$, and $215 \mathrm{~nm}$ and $343 \mathrm{~nm}$ are for cabbage-, carrot-, and tomato-extracted zinc oxide nanoparticles, respectively. These peaks are caused by $\mathrm{ZnO}$ NPs' surface plasmon absorption characteristics. When electromagnetic waves impact the surface plasmon absorption, a phenomenon happens owing to the cumulative oscillation of the open conduction band electrons $[17,18]$.

This current study of UV-visible absorption peak for $\mathrm{ZnO}$ NPs is similar to prior results [19]. Planck's equation was used to compute the bandgap energy $(E)$ of the produced $\mathrm{ZnO}$ nanoparticles.

$$
E=\frac{h c}{\lambda}
$$



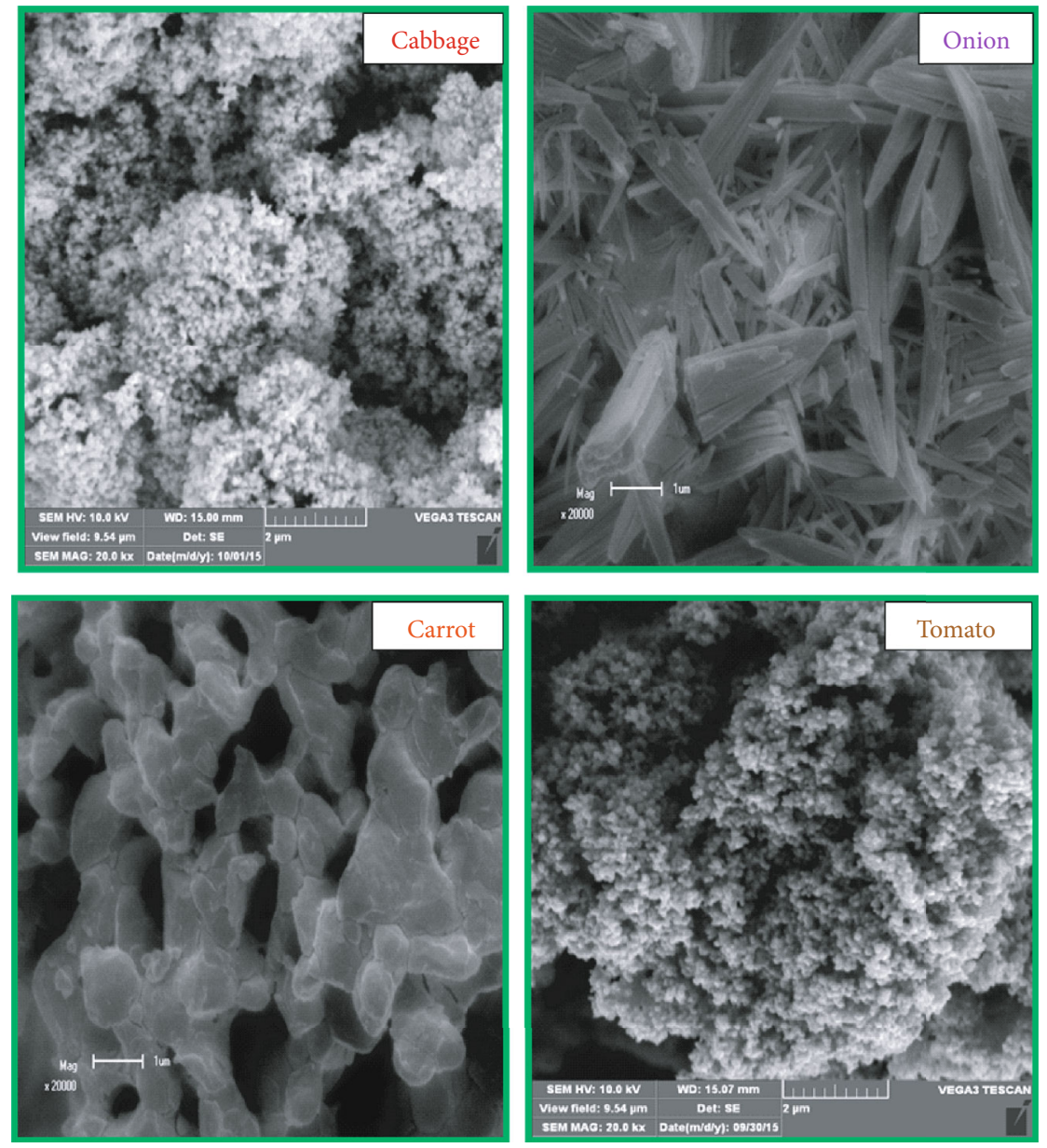

FIgURE 3: SEM images of the extracted ZnO NPs from onion, cabbage, carrot, and tomato through green synthesis methods.

TABLE 1: Average particle size, FWHM, and angle of diffraction of onion, cabbage, carrot, and tomato extracted from the prepared $\mathrm{ZnO}$ NPs.

\begin{tabular}{lccc}
\hline Extracted samples & 2 theta & FWHM $(\beta)$ & Average particle size $(t)$ \\
\hline Onion & 40.64 & 0.07345 & 17.10 \\
Cabbage & 40.64 & 0.05325 & 18.20 \\
Carrot & 40.64 & 0.04687 & 24.20 \\
Tomato & 40.64 & 0.08767 & 15.20 \\
\hline
\end{tabular}

where $E$ is the energy bandgap, $h$ is the Planck constant $=$ $6.626 \times 10^{-34} \mathrm{Js}, c$ is the speed of light $=3 \times 10^{8} \mathrm{~nm} \mathrm{~s}^{-1}$, and $\lambda$ is the wavelength.

Conversion of electron volt to joule is calculated as 1 $\mathrm{eV}=1.6 \times 10^{-19} \mathrm{~J}[20]$. Table 2 shows the computed bandgap energy value for greatest wavelengths. $\mathrm{ZnO}$ 's inherent bandgap absorption is caused by electron transitions between the valences to the conduction bands. Because $\mathrm{ZnO}$ nanoparticles absorb UV light, they can be employed in medicinal purposes such as sunscreen protection or antibacterial ointments [16]. A wide range of energy bandgaps was discovered in the $3-4 \mathrm{eV}$ range, indicating that $\mathrm{ZnO}$ NP powder can be employed in metal oxide semiconductor-based systems [19].
The characterization of the extracted zinc oxide nanoparticles was calculated using fill factor for dye-sensitive solar cell by using the following equation:

$$
f f=\frac{J_{\max } \times V_{\max }}{J_{\mathrm{sc}} \times V_{\mathrm{oc}}},
$$

where $J_{\max }, V_{\max }, J_{\mathrm{sc}}$, and $V_{\mathrm{oc}}$ represent the peak power point current density and voltage, small current density $\left(J_{\text {sc }}\right)$ of an observed current at $0 \mathrm{~V}$, and open-circuit voltage $\left(V_{\mathrm{oc}}\right)$, respectively [21].

The following Equation (4) calculates the energy conversion efficiency ( $n$ percent), which is the ratio of maximum power $\left(p_{\max }\right)$ to electrical input power $\left(p_{\text {in }}\right)$ :

$$
n=\frac{f f \times V_{\mathrm{oc}} \times J_{\mathrm{sc}}}{s \times p_{\mathrm{in}}},
$$

where " $s$ " is the area of dye-sensitive solar cell [22].

Figure 1 shows the electrical density $(j-v)$ curve of a dyesensitive solar module based on zinc oxide nanoparticles at various light intensities $(\mathrm{a}, \mathrm{b})$. DSSC variables like open voltage $\left(V_{\mathrm{oc}}\right)$, shorter-circuit current density $\left(J_{\mathrm{sc}}\right)$, fill factor $(f f$ ) , and efficiency $(n)$ were determined from the $j-v$ curves 


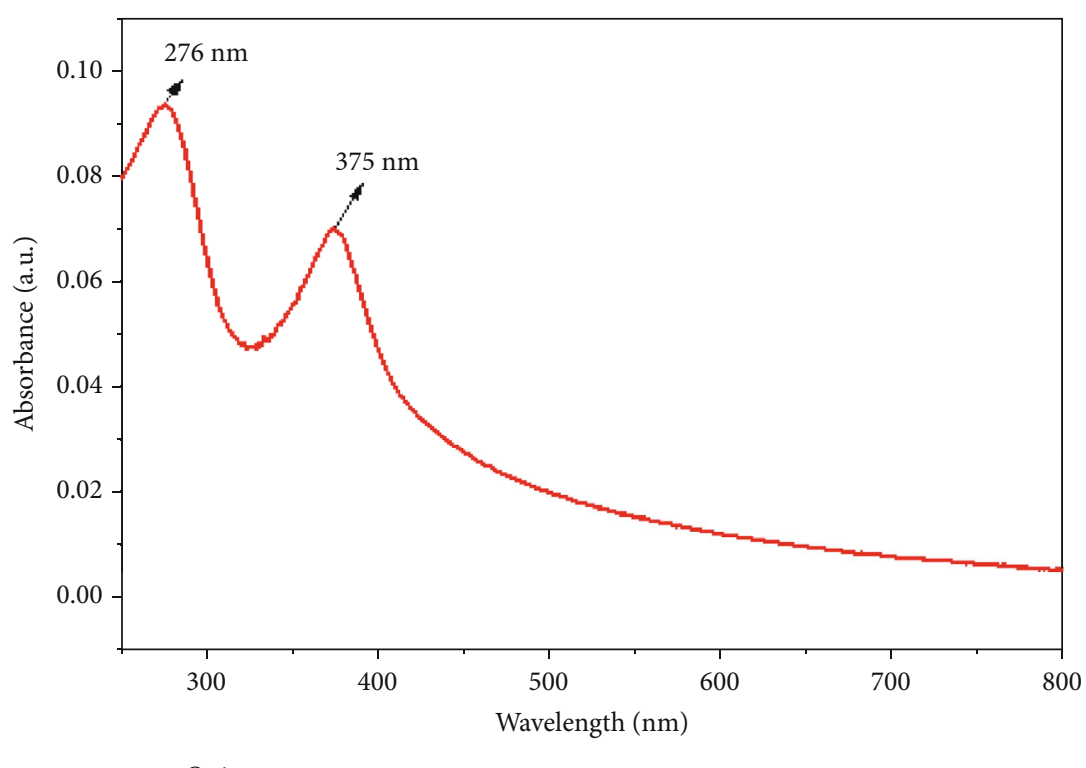

(a)

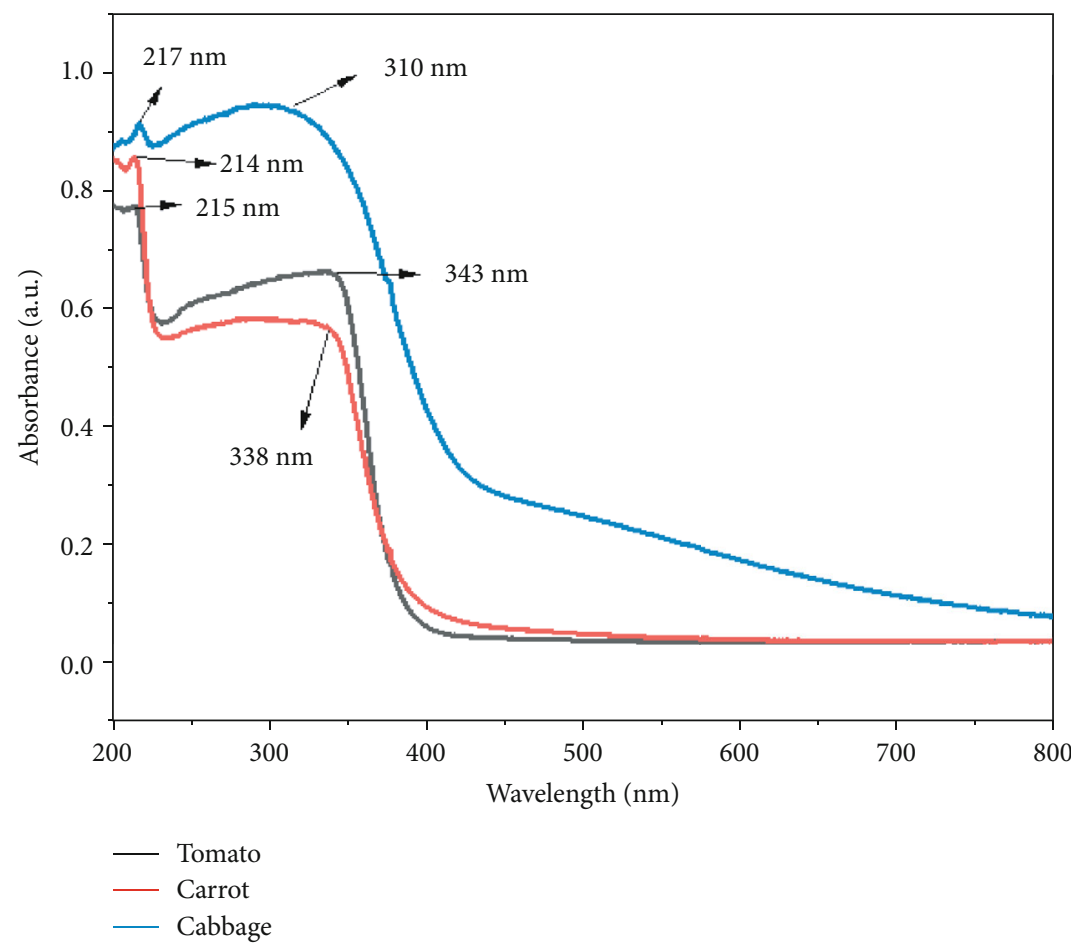

(b)

Figure 4: UV-visible absorbance spectra of the prepared ZnO NPs at (a) onion extraction and (b) cabbage, carrot, and tomato extractions.

TABLE 2: Energy bandgap of the prepared ZnO NPs extracted from onion, cabbage, carrot, and tomato.

\begin{tabular}{lcc}
\hline Extracted sample & Maximum wavelength & Energy bandgap \\
\hline Onion & $375 \mathrm{~nm}$ & $3.31 \mathrm{eV}$ \\
Cabbage & $310 \mathrm{~nm}$ & $4.01 \mathrm{eV}$ \\
Carrot & $338 \mathrm{~nm}$ & $3.68 \mathrm{eV}$ \\
Tomato & $343 \mathrm{~nm}$ & $3.62 \mathrm{eV}$ \\
\hline
\end{tabular}

using Equations (3) and (4). Table 1 shows the computed values for the DSSC parameters [23-33].

When compared to research having comparable $\mathrm{ZnO}$ nanoparticle architectures in the literature, it was discovered that the ZnO-based DSSC made $n$ percent quite good [22]. The immersion duration of $\mathrm{ZnO}$ NPs together into sensitizing dye had been demonstrated to be an important factor in the solar cell properties of the ZnO-based DSSC [34]. When compared to similar research [12-15], the manufactured $\mathrm{ZnO}$-based DSSC showed better performance in a lesser 
TABLE 3: Performance parameter of DSSC by the extracted ZnO NPs through green synthesizing methods.

\begin{tabular}{lcccccc}
\hline Extracted sample & $J_{\mathrm{sc}}\left(\mathrm{A} \mathrm{cm}^{-2}\right)$ & $V_{\mathrm{oc}}(\mathrm{V})$ & $J_{\max }\left(\mathrm{Acm}^{-2}\right)$ & $V_{\max }(\mathrm{V})$ & \multicolumn{1}{c}{$n^{-5}$} \\
\hline Onion & $6.22 \times 10^{-5}$ & 0.38 & $3.20 \times 10^{-5}$ & 0.26 & 0.38 & 0.0055 \\
Cabbage & $8.43 \times 10^{-5}$ & 0.22 & $4.21 \times 10^{-5}$ & 0.19 & 0.34 \\
Carrot & $2.99 \times 10^{-4}$ & 0.37 & $3.01 \times 10^{-4}$ & 0.30 & 0.0069 \\
Tomato & $6.01 \times 10^{-4}$ & 0.36 & $0.40 \times 10^{-4}$ & 0.28 & 0.080 \\
\hline
\end{tabular}

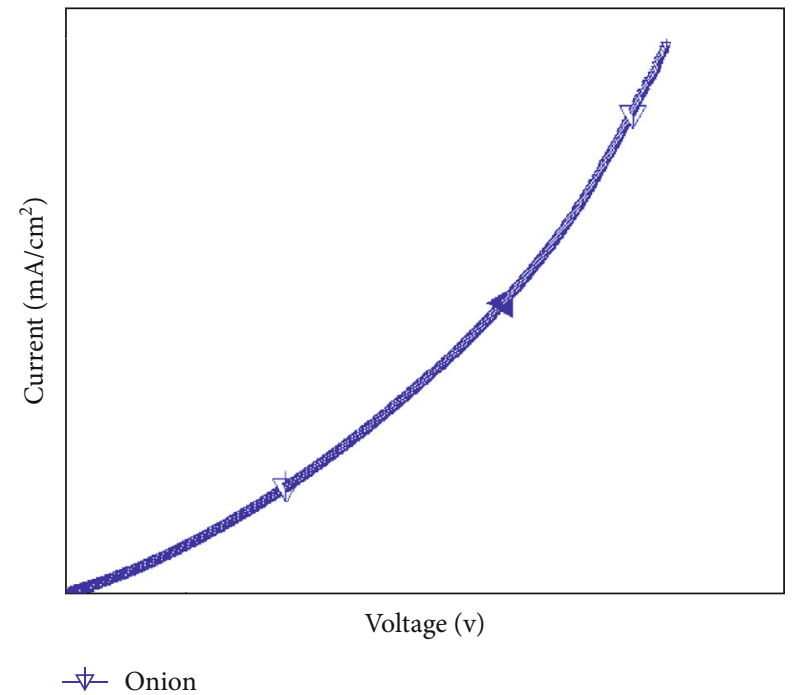

(a)

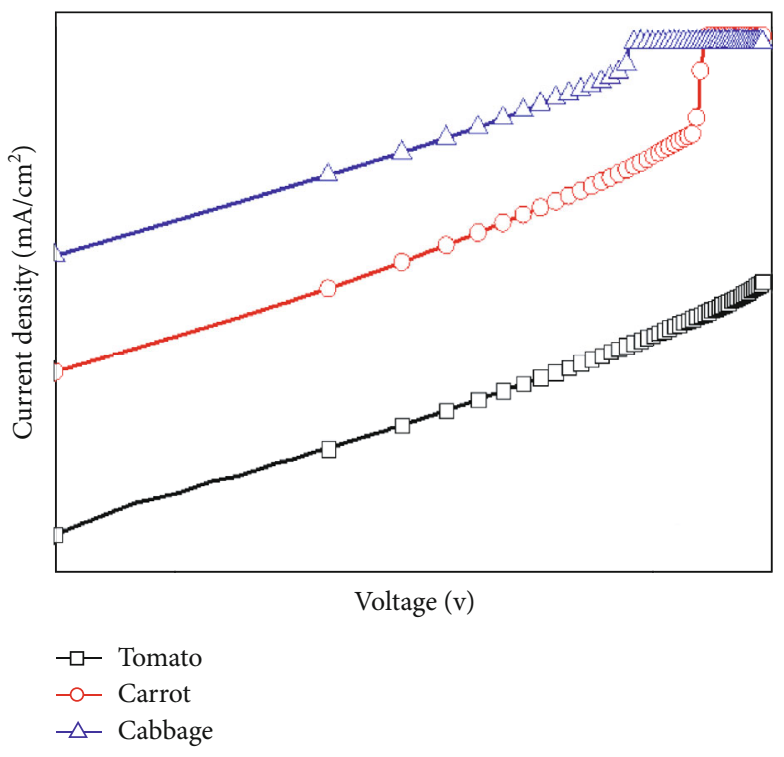

(b)

Figure 5: Current versus voltage curves of green synthesized ZnO NPs by (a) onion extract and (b) cabbage, carrot, and tomato extracts.

period of sinking time [35-44]. The enhanced absorption due to the larger amount and the better performance can also be expressed by the dye molecules that have been adsorbed onto the $\mathrm{ZnO}$ surface which can also expressed the better performance. As a result of the simplicity of the approach and the ease with which the specimens can be generated, through utilization of $\mathrm{ZnO}$ nanoparticles in photovoltaics seems to hold long-term prospects. The current density was discovered to be considerably lower. The photocurrent is the greatest significant parameter that defines the system's total performance limit. Then, because of their high surface area, parental substances act differently, and surface energy increases when the particle dimension is going towards that of a nanoscale [23, 24, 34]. The average crystallite dimensions of the $\mathrm{ZnO}$ nanoparticles were generated to be within $15 \mathrm{~nm}$ and $20 \mathrm{~nm}$. As a result, we can anticipate considerable photochemical characteristics. A low hardness factor, reflection or dispersion, minimal injection performance, and charge collecting efficiency can all contribute to a low [16-18]. As the light intensity rose, the shortcircuit voltage output grew progressive to near-saturation levels. Increased photogenerated excitons were linked to the linear increase in $J_{s c}[20-22,34,45]$. As a result, at greater light intensities, larger electron densities were transmitted to $\mathrm{ZnO}$. Table 3 shows that " $n$ " and " $J$ sc" readings improved even as applied light density has improved. The improvement in charge generation is a result of an elevation in light intensity. Comparable outcomes had previously been reported for $\mathrm{ZnO}$-based DSSC materials [19, 20, 45]. These findings reveal that increasing the intensity of illumination to $100 \mathrm{~mW} \mathrm{~cm}^{-2}$ has no effect on transport, injection, or recombination mechanisms as shown in Figure 5.

\section{Conclusion}

$\mathrm{ZnO}$ NPs were completely synthesized through simple and eco-friendly vegetable-mediated green synthesizing technique from onion, cabbage, carrot, and tomato fruit extraction. FTIR, XRD, SEM, and UV-visible spectroscopy were accustomed to characterize the produced nanopowders. The crystal structures of synthesized $\mathrm{ZnO}$ NPs were with particle sizes where observed from XDR results. According to Scherrer's equation, the produced $\mathrm{ZnO}$ NPs have a single-phase hexagonal geometry having mean particle sizes of $17 \mathrm{~nm}, 18 \mathrm{~nm}, 24 \mathrm{~nm}$, and $15 \mathrm{~nm}$. Small agglomeration of the extracted nanoparticles was observed from SEM results. Because extract capping agents are poisonous, they were not employed to minimize the clustering; nonetheless, the vegetable retrieving itself would work as a diminishing agent or a capping agent depending on the situation. As a result, the green synthesizing process is more cost-effective and environmentally friendly than conventional ways for 
producing $\mathrm{ZnO}$ NPs. The ZnO NP UV-visible spectroscopy revealed a large surface plasmon resonance absorption spike of the dye-sensitive solar cell based on ZnO NPs was effectively manufactured, and its performance was studied using current density-voltage behaviour below the influence of artificial sunlight. Due to a significant enhancement in dye molecule absorption upon this surface of ZnO NPs, a significant rise in the performance of the produced DSSC can be attributed to this. As a result, the employment of the green produced $\mathrm{ZnO}$ nanoparticles in the construction of dyesensitive solar cells is a simple and promising strategy for the future's well-being. $\mathrm{ZnO}$ nanoparticles can be used as intelligent weapons toward a wide range of drug-resistant microbes, as well as a capable antibiotic replacement.

\section{Data Availability}

The data used to support the findings of this study are included within the article.

\section{Conflicts of Interest}

The authors declare that there are no conflicts of interest

\section{References}

[1] H. Ahmad, K. Venugopal, K. Rajagopal et al., "Green synthesis and characterization of zinc oxide nanoparticles using Eucalyptus globules and their fungicidal ability against pathogenic fungi of apple orchards," Biomolecules, vol. 10, no. 3, p. 425, 2020.

[2] O. J. Nava, C. A. Soto-Robles, C. M. Gómez-Gutiérrez et al., "Fruit peel extract mediated green synthesis of zinc oxide nanoparticles," Journal of Molecular Structure, vol. 1147, pp. 1-6, 2017.

[3] S. Thakur, M. Shandilya, and G. Guleria, "Appraisement of antimicrobial zinc oxide nanoparticles through Cannabis Jatropha curcasa Alovera and Tinosporacordifolia leaves by green synthesis process," Journal of Environmental Chemical Engineering, vol. 9, no. 1, article 104882, 2021.

[4] S. Faisal, H. Jan, S. A. Shah et al., "Green synthesis of zinc oxide $(\mathrm{ZnO})$ nanoparticles using aqueous fruit extracts of Myristica fragrans: their characterizations and biological and environmental applications," ACS Omega, vol. 30, pp. 9709-9722, 2021.

[5] L. A. Kolahalam, K. R. Prasad, P. M. Krishna, and N. Supraja, "Saussurea lappa plant rhizome extract-based zinc oxide nanoparticles: synthesis, characterization and its antibacterial, antifungal activities and cytotoxic studies against Chinese Hamster Ovary (CHO) cell lines," Heliyon, vol. 7, no. 6, article e07265, 2021.

[6] K. M. Ezealisiji, X. Siwe-Noundou, B. Maduelosi, N. Nwachukwu, and R. W. M. Krause, "Green synthesis of zinc oxide nanoparticles using Solanum torvum (L) leaf extract and evaluation of the toxicological profile of the $\mathrm{ZnO}$ nanoparticles-hydrogel composite in Wistar albino rats," International Nano Letters, vol. 9, no. 2, pp. 99-107, 2019.

[7] B. Bekele, L. T. Jule, and A. Saka, "The effects of annealing temperature on size, shape, structure and optical properties of synthesized zinc oxide nanoparticles by sol-gel methods," Digest Journal of Nanomaterials \& Biostructures, vol. 16, no. 2, 2021.
[8] L. T. Jule, R. Krishnaraj, B. Bekele, A. Saka, and N. Nagaprasad, "Experimental investigation on the impacts of annealing temperatures on titanium dioxide nanoparticles structure, size and optical properties synthesized through sol-gel methods," Materials Today: Proceedings, vol. 45, pp. 5752-5758, 2021.

[9] A. Belay, B. Bekele, and A. C. Reddy, "Effects of temperature and polyvinyl alcohol concentrations in the synthesis of zinc oxide nanoparticles," Digest Journal of Nanomaterials \& Biostructures, vol. 14, no. 1, 2019.

[10] Q. Tang, H. Xia, W. Liang, X. Huo, and X. Wei, "Synthesis and characterization of zinc oxide nanoparticles from _Morus nigra_ and its anticancer activity of AGS gastric cancer cells," Journal of Photochemistry and Photobiology B: Biology, vol. 202, article 111698, 2020.

[11] D. Rehana, D. Mahendiran, R. S. Kumar, and A. K. Rahiman, "Evaluation of antioxidant and anticancer activity of copper oxide nanoparticles synthesized using medicinally important plant extracts," Biomedicine \& Pharmacotherapy, vol. 89, pp. 1067-1077, 2017.

[12] K. Ali, S. Dwivedi, A. Azam et al., "Aloe vera extract functionalized zinc oxide nanoparticles as nanoantibiotics against multi-drug resistant clinical bacterial isolates," Journal of Colloid and Interface Science, vol. 472, pp. 145-156, 2016.

[13] G. Pal, P. Rai, and A. Pandey, "Green synthesis of nanoparticles: a greener approach for a cleaner future," Green Synthesis, Characterization and Applications of Nanoparticles, vol. 548, pp. 1-26, 2019.

[14] S. Sarkar and R. Sarkar, "Synthesis, characterization and tribological study of zinc oxide nanoparticles," Materials Today: Proceedings, vol. 44, pp. 3606-3612, 2021.

[15] R. Verma, S. Pathak, A. K. Srivastava, S. Prawer, and S. Tomljenovic-Hanic, "ZnO nanomaterials: green synthesis, toxicity evaluation and new insights in biomedical applications," Journal of Alloys and Compounds, vol. 876, article 160175, 2021.

[16] S. C. Ezike, C. N. Hyelnasinyi, M. A. Salawu, J. F. Wansah, A. N. Ossai, and N. N. Agu, "Synergestic effect of chlorophyll and anthocyanin co-sensitizers in $\mathrm{TiO}_{2}$-based dye-sensitized solar cells," Surfaces and Interfaces, vol. 22, article 100882, 2021.

[17] B. Sahin, S. Soylu, M. Kara, M. Turkmen, R. Aydin, and H. Cetin, "Superior antibacterial activity against seed-borne plant bacterial disease agents and enhanced physical properties of novel green synthesized nanostructured $\mathrm{ZnO}$ using Thymbra spicata plant extract," Ceramics International, vol. 47, no. 1, pp. 341-350, 2021.

[18] M. Amde, Z. Q. Tan, R. Liu, and J. F. Liu, "Nanofluid of zinc oxide nanoparticles in ionic liquid for single drop liquid microextraction of fungicides in environmental waters prior to high performance liquid chromatographic analysis," Journal of Chromatography A, vol. 1395, pp. 7-15, 2015.

[19] S. Alamdari, M. Sasani Ghamsari, C. Lee et al., "Preparation and characterization of zinc oxide nanoparticles using leaf extract of Sambucus ebulus," Applied Sciences, vol. 10, no. 10, article 3620, 2020.

[20] A. T. Babu and R. Antony, "Green synthesis of silver doped nano metal oxides of zinc \& copper for antibacterial properties, adsorption, catalytic hydrogenation \& photodegradation of aromatics," Journal of Environmental Chemical Engineering, vol. 7, no. 1, article 102840, 2019.

[21] A. Ali, S. Ambreen, Q. Maqbool et al., "Zinc impregnated cellulose nanocomposites: synthesis, characterization and 
applications," Journal of Physics and Chemistry of Solids, vol. 98, pp. 174-182, 2016.

[22] D. Ayodhya and G. Veerabhadram, "One-pot green synthesis, characterization, photocatalytic, sensing and antimicrobial studies of Calotropis gigantea leaf extract capped CdS NPs," Materials Science and Engineering: B, vol. 225, pp. 33-44, 2017.

[23] M. A. Ansari and S. M. M. Asiri, "Green synthesis, antimicrobial, antibiofilm and antitumor activities of superparamagnetic $\gamma-\mathrm{Fe}_{2} \mathrm{O}_{3} \mathrm{NPs}$ and their molecular docking study with cell wall mannoproteins and peptidoglycan," International Journal of Biological Macromolecules, vol. 171, pp. 44-58, 2021.

[24] M. Faizan, J. A. Bhat, C. Chen et al., "Zinc oxide nanoparticles (ZnO-NPs) induce salt tolerance by improving the antioxidant system and photosynthetic machinery in tomato," Plant Physiology and Biochemistry, vol. 161, pp. 122-130, 2021.

[25] L. Tesfaye Jule, K. Ramaswamy, N. Nagaprasad, V. Shanmugam, and V. Vignesh, "Design and analysis of serial drilled hole in composite material," Materials Today: Proceedings, vol. 45, pp. 5759-5763, 2021.

[26] T. Amuthan, N. Nagaprasad, R. Krishnaraj, V. Narasimharaj, B. Stalin, and V. Vignesh, "Experimental study of mechanical properties of AA6061 and AA7075 alloy joints using friction stir welding," Materials Today: Proceedings, 2021.

[27] S. Abel, L. Tesfaye, B. Bekele, N. Nagaprasad, and R. Krishnaraj, "Studying the effect of metallic precursor concentration on the structural, optical, and morphological properties of zinc sulfide thin films in photovoltaic cell applications," Advances in Materials Science and Engineering, vol. 2021, Article ID 7443664, 6 pages, 2021.

[28] L. Tesfaye, B. Bekele, A. Saka, N. Nagaprasad, K. Sivaramasundaram, and R. Krishnaraj, "Investigating spectroscopic and structural properties of $\mathrm{Cr}$ doped $\mathrm{TiO}_{2} \mathrm{NPs}$ synthesized through sol gel deposition technique," Tierärztliche Praxis, vol. 41, pp. 860-872, 2021.

[29] E. K. Subramaniam, M. Sakthivel, K. Kanthavel, R. Krishnaraj, M. G. Deepan Marudachalam, and R. Palani, "Overall resource effectiveness, cycle time reduction \& capacity improvements," International Journal of Scientific and Engineering Research, vol. 2, no. 8, pp. 1-5, 2011.

[30] R. Sathiyamoorthy and R. Krishnaraj, "Optimization of cellular layout under dynamic demand environment by simulated annealing," International Journal of Scientific and Engineering Research, vol. 3, no. 10, pp. 1-7, 2012.

[31] V. M. M. Thilak, R. Krishnaraj, M. Sakthivel, K. Kanthavel, M. Marudachalam, and R. Palani, "Transient thermal and structural analysis of the rotor disc of disc brake," International Journal of Scientific and Engineering Research, vol. 2, no. 8, pp. 2-5, 2011.

[32] S. Varatharajan, R. Krishnaraj, M. Sakthivel, K. Kanthavel, M. G. Deepan Marudachalam, and R. Palani, "Design and analysis of single disc machine top and bottom cover," International Journal of Scientific and Engineering Research, vol. 2, no. 8, pp. 1-6, 2011.

[33] C. M. Balamurugan, R. Krishnaraj, M. Sakthivel, K. Kanthavel, D. Marudachalam, and R. Palani, "Computer aided modeling and optimization of crankshaft," International Journal of Scientific \& Engineering Research, vol. 2, no. 8, pp. 2-7, 2011.

[34] T. Zahra, K. S. Ahmad, C. Zequine et al., "Electro-catalyst $\left[\mathrm{ZrO}_{2} / \mathrm{ZnO} / \mathrm{PdO}\right]-\mathrm{NPs}$ green functionalization: fabrication, characterization and water splitting potential assessment," International Journal of Hydrogen Energy, vol. 46, no. 37, pp. 19347-19362, 2021.
[35] M. Vyshakh, R. K. Raj, A. P. Sayooj, and M. Afzal, "Experimental investigation on aluminium gravity die casting," International Journal of Applied Environmental Sciences, vol. 9, no. 2, pp. 213-222, 2014.

[36] M. Deepu, R. K. Raj, D. Karthik, and N. M. Binoj, "Cycle time optimization of rubber floor mat die," International Journal of Applied Environmental Sciences, vol. 9, no. 2, pp. 229-237, 2014.

[37] V. S. Arun, R. Krishnaraj, M. N. Rohit, and V. Mohan, "Optimising rejection rate of laser diamond sawing using Taguchi method," International Journal of Applied Environmental Sciences, vol. 9, no. 2, pp. 223-228, 2014.

[38] R. Krishnaraj, "Investigation on the effect of thermo physical properties on heat and mass transfer-review," International Journal of Applied Environmental Sciences, vol. 9, no. 4, pp. 1893-1900, 2014.

[39] C. N. Anil Kumar, R. Krishnaraj, M. Sakthivel, and M. Arularasu, "Implementation of safety education program for material handling equipment in construction sites and its effectiveness analysis using T-test," International Journal of Applied Environmental Sciences, vol. 8, no. 15, pp. 19611969, 2013.

[40] L. T. Jule, R. Krishnaraj, N. Nagaprasad, B. Stalin, V. Vignesh, and T. Amuthan, "Evaluate the structural and thermal analysis of solid and cross drilled rotor by using finite element analysis," Materials Today: Proceedings, 2021.

[41] B. Kassa, J. Leta Tesfaye, B. Bulcha et al., "Effect of Manganese Ions on Spectroscopic and Insulating Properties of Aluminophosphate Glasses," Advances in Materials Science and Engineering, vol. 2021, Article ID 6253069, 11 pages, 2021.

[42] N. Nagaprasad, B. Stalin, V. Vignesh, M. Ravichandran, N. Rajini, and O. Ismail, "Effect of cellulosic filler loading on mechanical and thermal properties of date palm seed/vinyl ester composites," International Journal of Biological Macromolecules, vol. 147, pp. 53-66, 2020.

[43] N. Nagaprasad, B. Stalin, V. Vignesh, M. Ravichandran, N. Rajini, and O. Ismail, "Applicability of cellulosic-based Polyalthia longigolia seed filler reinforced vinyl ester biocomposites on tribological performance," Polymer Composites, vol. 42, no. 2, pp. 791-804, 2020.

[44] B. Stalin, N. Nagaprasad, V. Vignesh, and M. Ravichandran, "Evaluation of mechanical and thermal properties of tamarind seed filler reinforced vinyl ester composites," Journal of Vinyl and Additive Technology, vol. 25, s2, pp. E114-E128, 2019.

[45] Z. Moradi Alvand, H. R. Rajabi, A. Mirzaei, A. Masoumiasl, and H. Sadatfaraji, "Rapid and green synthesis of cadmium telluride quantum dots with low toxicity based on a plantmediated approach after microwave and ultrasonic assisted extraction: synthesis, characterization, biological potentials and comparison study," Materials Science and Engineering: C, vol. 98, pp. 535-544, 2019. 